\title{
R-CVP Regimen
}

National Cancer Institute

\section{Source}

National Cancer Institute. R-CVP Regimen. NCI Thesaurus. Code C63473.

A regimen consisting of rituximab, cyclophosphamide, vincristine, and prednisone used to treat indolent non-Hodgkin's lymphoma. 